\title{
Daño moral por intromisión ilegítima en el derecho al honor como consecuencia de la inclusión indebida en registros de morosos*
} by unlawful interference in the right
to honour as a consequence of wrongful
inclusion on debtors'registers

\author{
lsabel Espín Alba**
}

\section{RESUMEN}

La inclusión de los datos de un deudor en los ficheros de información de solvencia patrimonial y crédito, también denominados registros de morosos, puede ocasionar un impacto extremadamente negativo en su reputación personal y profesional. En los últimos años, el Tribunal Supremo español pudo construir una doctrina sobre la indemnización por daños causados por intromisión ilegítima en el derecho al honor por inclusión indebida en registros de morosos. El objeto del presente artículo es estudiar esa doctrina jurisprudencial, destacando el problema del valor simbólico de las indemnizaciones planteadas, pues este tipo de cuantificación es disuasoria para los afectados por la inclusión indebida. En ese sentido, se analiza la función del derecho de daños en estos supuestos, avanzando alguna reflexión sobre el valor preventivo de ciertos mecanismos del Reglamento Europeo de Protección de Datos, en aras del fortalecimiento de una cultura jurídica de la prevención.

PALABRAS CLAVE: Datos personales, registro de morosos, derecho al honor, derecho de daños, daños morales.

\begin{abstract}
The inclusion of the details of a debtor on the indexes containing information on solvency and creditworthiness, also known as debtors' registers, may have an extremely negative impact on their personal and professional reputation. In recent years, the Spanish Supreme Court has been able to construct a doctrine on the compensation for damages caused by unlawful interference in the right to honour as a consequence of wrongful inclusion on debtors' registers. The present article aims to study this jurisprudential doctrine, highlighting the problem of the symbolic value of the compensation awarded, as this type of quantification is a deterrent for those damaged by said wrongful inclusion. Thus, the present article analyses the function of tort law in these cases, presenting reflections on the preventive value of certain mechanisms pertaining to the European Data Protection Regulations, in an effort to strengthen a preventive legal culture.
\end{abstract}

KEY WORDS: Personal data. debtors' register. right to honor. right to damages/tort law. nonmaterial damages.

\footnotetext{
* Artículo de investigación. Recibido el 27 de septiembre de 2018 y aceptado para su publicación el 24 de junio de 2019.

** Profesora titular de Derecho Civil en la Universidad de Santiago de Compostela, España. (isabel.espin@usc.es) orcid.org/0000-0003-0624-6290
} 


\section{SUMARIO}

1. Los ficheros de solvencia patrimonial y el sistema de crédito

2. Protección de datos personales y registros de morosos

3. Tratamiento jurisprudencial de la inclusión indebida en un registro de morosos

4. El principio de calidad de los datos personales

5. El honor como derecho fundamental vulnerado

6. Alcance de la reparación: daños patrimoniales y morales

7. Daños morales e indemnizaciones simbólicas

8. Conclusiones

\section{Los ficheros de solvencia patrimonial y el sistema de crédito}

La crisis financiera ha movido los cementos de muchas instituciones del derecho patrimonial que tuvieron que acomodarse a los nuevos y complejos conflictos surgidos por la generalizada situación de insolvencia de un número elevado de agentes económicos en el mercado, empresas o consumidores. Con ello, ha obligado a una incansable labor de creación y adaptación jurídica.

Los protagonistas del problema jurídico en el presente estudio son, por un lado, personas que han visto sus datos indebidamente incluidos en ficheros de información crediticia (por lo general, consumidores o pequeñas empresas, aunque nos centremos en los primeros); por otro, las empresas que se presentan como acreedoras de las deudas y aquellas que realizan el tratamiento de los datos para proporcionar información crediticia a terceros.

Esta situación puede provocar innegables consecuencias negativas para aquellos cuyos datos fueron incluidos indebidamente en el registro de morosos, por lo pronto por el desprestigio personal y profesional y, más concretamente, por la pérdida de capacidad crediticia que se puede reflejar en la no concesión de créditos futuros o en el encarecimiento de estos.

Abordaremos las implicaciones jurídicas, desde el prisma de la responsabilidad por los daños causados por las empresas acreedoras que proporcionaron los datos y por aquellas responsables del tratamiento de los mismos. Para ello, es preciso poner de manifiesto la legitimación en el ordenamiento jurídico español de los ficheros de solvencia patrimonial negativa.

El préstamo responsable y la evaluación de la solvencia han adquirido, en los últimos años, un papel destacado en el apuntalamiento del sistema crediticio. $\mathrm{Su}$ finalidad es evitar que vuelvan a suceder situaciones incontroladas de 
sobreendeudamiento e insolvencia de consumidores, consecuencia de la concesión ilimitada e irresponsable de créditos de alto riesgo. ${ }^{1}$

En la legislación española de contratos de crédito al consumo, el artículo 15 de la Ley 16/2011, de 24 de junio, dedicado al acceso a las bases de datos de solvencia patrimonial, configura dicho acceso como un instrumento de particular interés en las relaciones precontractuales, ${ }^{2}$ pues facilitan la evaluación de los riesgos del préstamo. ${ }^{3}$

De ese modo, los registros de morosos son una herramienta más para el análisis del comportamiento crediticio dedicado esencialmente al crédito minorista. Son sistemas de información crediticia centrados en pequeños acreedores, cuya actividad básica es proveer información negativa sobre el incumplimiento de deudas de los potenciales solicitantes de créditos. ${ }^{4}$

En la Sentencia de la Audiencia Provincial (SAP) de A. Coruña, de 23 de marzo de 2018, en la senda marcada por la jurisprudencia de la Sala $1^{\text {a }}$ del Tribunal Supremo, los registros de morosos son definidos como:

Ficheros automatizados (informáticos) de datos de carácter personal sobre incumplimiento de obligaciones dinerarias, destinados a informar a los operadores económicos (no solo a las entidades financieras, también a otro tipo de empresas que conceden crédito a sus clientes o cuyas prestaciones son objeto de pagos periódicos) sobre qué clientes, efectivos o potenciales, han incumplido obligaciones dinerarias anteriormente, para que puedan adoptar fundadamente sus decisiones sobre las relaciones comerciales con tales clientes.

\footnotetext{
'Véase Álvarez Olalla, Pllar, "La obligación de evaluar la solvencia y su incumplimiento", en Matilde Cuena Casas y Vicente Alcañiz Miñano, La prevención del sobreendeudamiento privado. Hacia un préstamo y consumo responsables, Cizur Menor, Thomson Reuters Aranzadi, 2017, pp. 725-810.

${ }^{2}$ Artículo 14.1 de la Ley 16/2011: "El prestamista, antes de que se celebre el contrato de crédito, deberá evaluar la solvencia del consumidor, sobre la base de una información suficiente obtenida por los medios adecuados a tal fin, entre ellos, la información facilitada por el consumidor, a solicitud del prestamista o intermediario en la concesión de crédito. Con igual finalidad, podrá consultar los ficheros de solvencia patrimonial y crédito, a los que se refiere el artículo 29 de la LOPD, en los términos y con los requisitos y garantías previstos en dicha Ley Orgánica y su normativa de desarrollo."

${ }^{3}$ Se puede consultar también el artículo 29 de la Ley 2/2011, de 4 de marzo, de Economía Sostenible y el artículo 18 de la Orden EHA/2899/2011, de 28 de octubre, de transparencia y protección del cliente de servicios bancarios, bajo el epígrafe "préstamo responsable". Asimismo, los artículos 1, 11 y 12, de la Ley 5/2019, de 15 de marzo, de contratos de crédito inmobiliario.

${ }^{4}$ A diferencia del sistema norteamericano, en el español no existe aportación positiva. Matilde Cuena explica que "El que fue moroso en tiempo pasado puede 'rehabilitarse' con un comportamiento correcto presente. La información positiva reciente tiene más valor que la información negativa del pasado. Con ello se pretende constituir un estímulo al buen comportamiento". CUenA CASAS, MatlLDE, "Fresh Start y mercado crediticio", InDret, núm. 3, pp. 36 y 43.
} 
En España, desde el punto de vista de los consumidores, los más destacados son Asnef-Equifax, que agrupan un amplio abanico de entidades financieras, compañias de telefonía, empresas de suministros y aseguradoras, y BadexcugExperian, que contiene información proporcionada por bancos, cajas de ahorro, cooperativas de crédito y establecimientos financieros de crédito que estén obligados a declarar a la Central de Riesgos del Banco de España (Cirbe), ${ }^{5}$ y operadoras de telecomunicaciones. El RAI (Registro de Adeudos Impagados) incluye exclusivamente datos de personas jurídicas.

Ahora bien, a pesar de que tales ficheros son contemplados por distintas normas que los legitiman, la existencia misma y el acceso a esos registros deben ser, en todo caso, acordes con la legislación de protección de datos de carácter personal.

En este punto, será obligado sopesar el interés y la obligación empresarial en conocer la solvencia de una persona en relación con la prohibición de intromisiones ilegítimas en el derecho a su honor y en la protección de sus datos personales.

El problema que se viene perfilando en la práctica reside en que la frontera entre esa utilización legítima del tratamiento de los datos de insolvencia y la violación de derechos fundamentales de los afectados por la inclusión se desdibuja. Debemos tomar en cuenta que las empresas acreedoras utilizan esos registros, más allá de su función conformadora de un crédito responsable, como un instrumento de presión sobre los deudores.

Esa finalidad coactiva debe estar fuera del discurso legitimador de la inclusión de datos negativos de solvencia en los registros al efecto.

De hecho, la jurisprudencia casacional civil, en más de una ocasión, ${ }^{6}$ se ha referido a la inclusión en esos ficheros como un medio extraordinario, accesorio y de presión para conseguir el cobro de una deuda, fundamentado en el temor al descrédito personal y profesional del afectado o en la denegación del acceso $\mathrm{u}$ obstaculización del acceso al sistema crediticio que supone aparecer en un registro de morosos. Una auténtica presión ilegítima, en definición de la STS (Sala 1a), de 23 de marzo de 2018.

Describe muy bien la situación la SAP de Palencia del 26 de abril de 2018 cuando explica que las compañías de telefonía deben proporcionar datos sobre deudas ciertas, vencidas y exigibles para el tratamiento por los registros de solvencia patrimonial, y no utilizar esa cesión como un medio de coacción al

\footnotetext{
${ }^{5}$ La jurisprudencia considera que la Cirbe no es propiamente un fichero de datos de carácter personal, en la medida en que se trata de un fichero administrativo sobre los riesgos de crédito. ssts (Sala 1ª) 29 de enero, 2014, 1 de marzo, 2016 y 2 de noviembre, 2017.

${ }^{6}$ Cfr. ssts (Sala 1a) de 16 de febrero, 2016, 22 de enero, 2014, 6 de marzo, 2013.
} 
pago de una deuda, ni de particulares, ni de empresas. "Lo contrario supone una actuación irregular, que atenta contra el buen nombre y reputación del afectado y que le otorga al mismo el derecho de instar la cancelación de dichos datos y una indemnización por la intromisión ilegítima en su honor."

En suma, los registros de morosos son parte del sistema de crédito y son vistos como una forma legítima de ofrecer información sobre la potencialidad crediticia de las personas. ${ }^{7}$ Asimismo, no se confunde con métodos coactivos, como por ejemplo la divulgación indiscriminada de la solvencia económica de un sujeto. ${ }^{8}$

Por todo ello, el objeto del presente artículo es estudiar esa doctrina jurisprudencial que reconoce que es una intromisión ilegitima en el honor del afectado la inclusión indebida en un registro de morosos. Destaca el problema del valor simbólico de algunas indemnizaciones planteadas, sin dejar de avanzar alguna reflexión sobre el valor preventivo de ciertos mecanismos del Reglamento Europeo de Protección de Datos (REPD), ${ }^{9}$ en aras del fortalecimiento de una cultura jurídica de la prevención.

\section{Protección de datos personales y registros de morosos}

Para situarse en los parámetros de legitimidad exigibles, los ficheros de morosos deben cumplir escrupulosamente con la normativa de protección de datos personales.

El artículo 18.4 de la Constitución Española (CE) establece que "la ley limitará el uso de la informática para garantizar el honor y la intimidad personal y familiar de los ciudadanos y el pleno ejercicio de sus derechos", conformando, por la interpretación del Tribunal Constitucional, un verdadero derecho fundamental.

La doctrina constitucional en materia de solvencia patrimonial y protección de datos aboga por considerar parte de la esfera de la intimidad familiar y personal los datos económicos y bancarios de una persona. Sin embargo, no se trata de una reserva absoluta $;{ }^{10}$ puede estar legítimamente limitada, como en

\footnotetext{
${ }^{7}$ La Resolución de 22 de enero de 2001 de la Agencia Española de Protección de Datos reconoce que este tipo de ficheros contribuyen, sin duda, a la salvaguarda del sistema financiero y de la economía en general.

${ }^{8}$ Sobre este extremo, se puede recordar la sts (Sala 1a) del 30 de abril, 1995, que consideró una intromisión ilegítima la remisión por parte del acreedor de una carta a su deudor, en la que se podia leer en el envés externo del sobre: "Insistimos en la necesidad de que se ponga en contacto con nosotros y pague lo que debe factura. 'Muebles La Areuyense' de 487.948".

${ }^{9}$ Reglamento (UE) 2016/679 del Parlamento Europeo y del Consejo, de 27 de abril de 2016, relativo a la protección de las personas fisicas en lo que respecta al tratamiento de datos personales y a la libre circulación de estos datos (Diario Oficial de la Unión Europea de 4 de mayo de 2016).

${ }^{10}$ Parra Lucan, M. Ángeles, "Vulneración del derecho al honor por incorrecta inclusión en un fichero de morosos: Sentencia del Tribunal Supremo de 24 de abril del 2009", en Mariano Yzquierdo Tolsada (dir.), Comentarios a las sentencias de unificación de doctrina: civil y mercantil, Madrid, Dykinson, 2009, p. 474.
} 
el asunto que nos ocupa. En todo caso, el habeas data se configura a partir de su contenido positivo que permite exigir a terceros un comportamiento, pero también negativo, en el sentido de que no incluye datos erróneos o que vulneren derechos.

En lo que concierne a la protección de datos personales, en particular, los ficheros sobre solvencia patrimonial y crédito y los de cumplimiento e incumplimiento de obligaciones económicas, la normativa de protección de datos establece una serie de obligaciones para que el tratamiento de esa información sea legítimo.

Tales requisitos están recogidos en el artículo 20 de la vigente Ley Orgánica de Protección de Datos (LOPD) de 2018, ${ }^{11}$ promulgada para adaptarse a la entrada en vigor del REPD. Este precepto es heredero del derogado artículo 29 LoPD de 1999 y de la doctrina jurisprudencial que, a continuación, se comenta. Así las cosas, impone a los sistemas de información crediticia las siguientes condiciones para la licitud del tratamiento de datos:

- Que los datos hayan sido facilitados por el acreedor o por quien actúe por su cuenta o interés.

- Que los datos se refieran a deudas ciertas, vencidas y exigibles, cuya existencia o cuantía no hubiese sido objeto de reclamación administrativa o judicial por el deudor o mediante un procedimiento alternativo de resolución de disputas vinculante entre las partes.

- Que el acreedor haya informado al afectado en el contrato o en el momento de requerir el pago acerca de la posibilidad de inclusión en dichos sistemas, con indicación de aquéllos en los que participe. ${ }^{12}$

- Que los datos únicamente se mantengan en el sistema mientras persista el incumplimiento, con el límite máximo de cinco años desde la fecha de vencimiento de la obligación dineraria, financiera o de crédito.

- Que los datos referidos a un deudor determinado solamente puedan ser consultados cuando quien consulte el sistema mantuviese una relación contractual con el afectado que implique el abono de una cuantía pecuniaria o este le hubiera solicitado la celebración de un contrato que suponga financiación, pago aplazado o facturación periódica, como

\footnotetext{
11 Ley Orgánica 3/2018, de 5 de diciembre, de Protección de Datos Personales y garantía de los derechos digitales, Boletin Oficial del Estado, 6 de diciembre, 2018.

${ }^{12}$ La entidad que mantenga el sistema de información crediticia con datos relativos al incumplimiento de obligaciones dinerarias, financieras o de crédito deberá notificar al afectado la inclusión de tales datos y le informará sobre la posibilidad de ejercitar los derechos establecidos en los artículos 15 a 22 del REPD dentro de los treinta dias siguientes a la notificación de la deuda al sistema, permaneciendo bloqueados los datos durante ese plazo.
} 
sucede, entre otros supuestos, en los previstos en la legislación de contratos de crédito al consumo y de contratos de crédito inmobiliario. ${ }^{13}$

- Que, en el caso de que se denegase la solicitud de celebración del contrato, o éste no llegara a celebrarse, como consecuencia de la consulta efectuada, quien haya consultado el sistema informe al afectado del resultado de dicha consulta.

Es preciso tener en cuenta que corresponderá al acreedor garantizar que concurren los requisitos exigidos para la inclusión en el sistema de la deuda, respondiendo de su inexistencia o inexactitud.

\section{Tratamiento jurisprudencial de la inclusión indebida en un registro de morosos}

Hasta fechas recientes, el tratamiento de datos por los registros de morosos había sido objeto de conflicto principalmente desde el punto de vista administrativo. Así se puede observar en el amplio repertorio de decisiones relativas a sanciones impuestas por la Agencia Española de Protección de Datos, y en el repertorio de sentencias de la Sala $3^{a}$ (Contencioso Administrativo) del Tribunal Supremo (Ts) y de la Sala de lo Contencioso-Administrativo de la Audiencia Nacional. ${ }^{14}$

Con todo, la inestabilidad económica de los últimos tiempos aumentó sobremanera las quejas sobre inclusiones indebidas de los datos de las personas en ficheros de insolvencia, desde la perspectiva de los daños causados al honor del afectado.

La situación conflictiva que se repite con demasiada frecuencia tiene lugar cuando se le comunica a una persona la no concesión de un crédito o la exigencia de mayores garantías para ello, como consecuencia de su inclusión en un fichero de morosos. En no pocas ocasiones es precisamente en ese momento

\footnotetext{
${ }^{13}$ Cuando se hubiera ejercitado ante el sistema el derecho a la limitación del tratamiento de los datos impugnando su exactitud conforme a lo previsto en el artículo 18.1. a) del REPD, el sistema informará a quienes pudieran consultarlo con arreglo al párrafo anterior acerca de la mera existencia de dicha circunstancia, sin facilitar los datos concretos respecto de los que se hubiera ejercitado el derecho, en tanto se resuelve sobre la solicitud del afectado.

${ }^{14}$ Para un acercamiento a la problemática administrativa del ejercicio de los derechos ARco (Acceso, Rectificación, Cancelación y Oposición), incluido el derecho al olvido introducido por el REPD, se pueden consultar los Informes y Resoluciones de la Agencia Española de Protección de Datos, disponibles en www.aepd.es.
} 
cuando el afectado se entera de que figura en un registro de esas características, pues no se le había notificado debidamente el tratamiento de sus datos. ${ }^{15}$

La doctrina jurisprudencial generada en la jurisdicción civil y objeto del presente análisis crítico se centra en la violación del derecho al honor. En ella no se desconoce el valor y legitimidad de los ficheros de solvencia económica, sino que se plantea alguna de sus disfunciones que, corregidas, pueden implicar una mayor fortaleza y rigor del sistema.

Sin ánimo exhaustivo, consideraron la existencia de vulneración del derecho al honor las SSTs (Sala 1) de 5 de julio de 2004, 9 de abril de 2012, 29 de enero y 6 de marzo de 2013, 22 de enero, 21 de mayo, 5 de junio, 19 de noviembre y 4 de diciembre de 2014, 18 de febrero, 12 de mayo, y 22 de diciembre de 2015, 16 de febrero de 2016, 26 de abril y 21 de septiembre de 2017, 23 de marzo, 21 de junio, 6 y 7 de noviembre de 2018, y 20 de febrero, 23 y 25 de abril de 2019. Merece ser destacada la sTs 24 de abril de 2009 (Sección Pleno) en cuanto marcó el paso de esta doctrina jurisprudencial.

La cuestión reside en que, para considerar que no hubo una intromisión ilegítima, es preciso, en primer lugar, averiguar si la actuación no está amparada por la Ley. El artículo 2.2 de la Ley Orgánica 1/1982 determina que "no se apreciará existencia de intromisión ilegítima en el ámbito protegido cuando estuviere expresamente autorizada por ley".

Por todo ello, la jurisprudencia señalada invita a reseñar, a continuación, los principales elementos de la doctrina jurisprudencial civil en la materia. El punto de partida es el principio de calidad de los datos que justifica y fundamenta la legitimidad de la publicación del perfil negativo de solvencia económica en los ficheros de morosos, para después concretar los requisitos para que se reconozca una intromisión ilegítima en el honor de la persona afectada por la inclusión de sus datos en tales ficheros, y el consecuente alcance de la indemnización por los daños materiales y morales causados.

\footnotetext{
${ }^{15} \mathrm{El}$ artículo 11.6 de la Ley 5/2019, de 15 de marzo de crédito inmobiliario, determina que "Cuando se deniegue la solicitud de préstamo, el prestamista informará por escrito y sin demora al potencial prestatario y, en su caso, al fiador o avalista de su respectivo resultado advirtiéndoles, de forma motivada de dicha denegación y, si procede, de que la decisión se basa en un tratamiento automático de datos. Cuando la denegación se base en el resultado de una consulta de una base de datos entregará una copia del resultado, el prestamista informará también al potencial prestatario del resultado de dicha consulta y de los pormenores de la base de datos consultada, como son el nombre, el responsable, así como del derecho que le asiste de acceder y rectificar, en su caso, los datos contenidos en la misma".
} 


\section{El principio de calidad de los datos personales}

La LOPD de 2018 conoce la importancia de la información sobre la solvencia para el diseño y mantenimiento de un sistema crediticio fuerte y transparente. Por eso, su artículo 20.1 presume lícito ${ }^{16}$ el tratamiento de datos personales relativos al incumplimiento de obligaciones dinerarias, financieras o de crédito por sistemas comunes de información crediticia cuando se cumplan los requisitos señalados, en especial, la calidad de los datos tratados. ${ }^{17}$

La preocupación por la calidad proviene de la propia esencia de ese tipo de ficheros ${ }^{18} \mathrm{y}$ de las disfunciones, en gran medida derivadas de que se nutren de información proporcionada por la parte interesada. ${ }^{19}$ Está reflejada en los citados apartados b), c) y d) del artículo 20 Lopd de 2018. Así, encontramos la exigencia de que se trate de deuda cierta, vencida y exigible, que el acreedor haya informado en el contrato o en el momento de requerir el pago sobre la posible inclusión en el fichero, y que los datos se mantengan en el mismo por un máximo de cinco años.

Sobre el primer requisito, la STS (Sala 1a) de 29 de enero de 2013 hace hincapié en que la legislación de protección de datos "descansa en principios de prudencia, ponderación y sobre todo, de veracidad, de modo que los datos objeto de tratamiento deben ser auténticos, exactos, veraces y deben estar siempre actualizados”. ${ }^{20}$ Por ello, las ssts (Sala 12) de 9 de abril 2012, 29 de enero

\footnotetext{
${ }^{16}$ En este punto, hubo un cambio de paradigma en el análisis de la calidad de los datos, pues el derogado artículo 29 LOPD DE 1999 decía que el tratamiento "será lícito", mientras que ahora, la vigente LOPD de 2018 establece una presunción iuris tantum cuando dice "salvo prueba en contrario, se presumirá lícito". Cfr. MAS BADIA, MA. DoloRES, "Los sistemas de información crediticia y la protección de datos personales: un Reglamento europeo y una Ley Orgánica concebida y no nacida", Actualidad Civil, núm. 5.

${ }^{17}$ Explica la excepcionalidad de la recogida de datos y la consecuente necesidad de apuntalar un riguroso análisis de la calidad de datos la sts (Sala 1a) de 22 de enero, 2014.

${ }^{18}$ El derogado artículo 29 de la LOPD regulaba, por un lado, los ficheros de solvencia patrimonial y crédito; por otra, los ficheros de cumplimiento o incumplimiento de obligaciones dinerarias. Estos últimos son los registros de morosos que se nutren de la información proporcionada por una parte interesada y los acreedores, sin pasar por ningún tipo de filtro a modo de auditoría de los datos presentados para su tratamiento.

Esta disfunción original genera una casuistica de inclusiones indebidas que se pueden reconducir, como indica Chaparro Matamoros, a alguna de las siguientes situaciones: un error al atribuir a una persona una deuda que no es suya, en muchas ocasiones como consecuencia de la suplantación de su identidad, la inclusión de deudas no vencidas o no exigibles por cualquier otro motivo, controversias sobre la cantidad debida, o deudas no requeridas previamente por el acreedor. Cfr. Chaparro Matamoros, Pedro, "Sentencia de 12 mayo 2015", Cuadernos Civitas de Jurisprudencia Civil, núm. 100, pp. 357-382.

${ }^{19}$ Hualde Manso, Maria Teresa, "Ficheros de morosos, nulidad del Reglamento de Protección de Datos y derecho al honor", Revista Doctrinal Aranzadi Civil-Mercantil, vol. 2, núm. 8, p. 49.

${ }^{20}$ En la SAP de Cantabria de 11 de enero de 2018 se consideró que no se respetaron los principios de prudencia y proporcionalidad, ya que los datos no eran determinantes para enjuiciar la solvencia económica, incluso porque no eran veraces ni exactos pues no existía una deuda concreta, cierta, vencida, exigible por importe de 780 euros, sino una reclamación derivada de su unilateral y errónea liquidación en demanda de juicio monitorio.
} 
2013, 22 y 29 de enero, 21 de mayo, 4 y 5 de junio y 19 de noviembre 2014, 3 de diciembre de 2014, 18 de febrero, 12 de mayo, 16 de julio, 22 de diciembre de 2015, y 1 de marzo 2016, entre otras, se basan en que se había incluido erróneamente a las personas afectadas como deudores en un registro, cuando no lo eran, porque las deudas no se mostraron exactas y veraces.

Consiguientemente, contrario sensu, cuando se demuestra la existencia previa de una deuda cierta, vencida, exigible, que haya resultado impagada, no se entenderá ilegítima la inclusión de datos en los ficheros. Esto ocurrió, entre otras, en las SsTs (Sala $1^{\text {a) }}$ de 29 de enero de 2014 y 2 de noviembre de 2017. Resulta ilustrativo el caso de la STs (Sala $1^{\text {a) }}$ de 1 de marzo de 2016 que entiende que se cumplieron todos los requisitos de licitud cuando se incluyeron los datos de la demandante en el fichero de morosidad Badexcug-Experian y la anotación del riesgo moroso en el fichero Cirbe del Banco de España, puesto que era veraz que había sido fiadora de un crédito no pagado por el deudor principal. Asimismo, en el conflicto descrito en la SAP de Vizcaya de 4 de mayo de 2017 no hubo error porque el deudor lo era cuando fue incluido en el registro, y lo seguía siendo por ocasión de la demanda.

Sobre el requerimiento del pago, tiene interés la sTs (Sala $1^{\text {a) }}$ de 12 de mayo de 2015 que fija en 10000 euros para cada uno de los actores pese a que existía la deuda que se redujo ligeramente en una junta arbitral, pero no constaba cumplido el requisito del requerimiento. También sobre la exigencia esencial del previo requerimiento de pago, en la SAP de Madrid de 25 de enero de 2018 no hay constancia suficiente de que el demandado recibiera las comunicaciones que se dicen remitidas, pues "la mera remisión de cartas tal y como se ha hecho no es bastante a los fines que nos ocupan”. Tampoco en la sTs (Sala $1^{\text {a) }}$ de 25 de abril de 2019 que destaca el papel esencial del requerimiento, a los efectos del ejercicio de los derechos de acceso, rectificación, oposición y cancelación. ${ }^{21}$

El legislador no hace ninguna mención a un importe mínimo de la deuda. Con ello, pone en duda que la inclusión en un fichero de morosos de una deuda de escaso importe pueda retratar la solvencia de una persona. No obstante, la STs (Sala 1a) de 19 de noviembre de 2014 zanjó la polémica; mantuvo que la inclusión de una deuda pequeña, siempre que la misma sea cierta, exacta y no esté sujeta a una controversia razonable, es acorde con la finalidad de esos registros, pues es indicativa de una posible insolvencia del afectado.

\footnotetext{
${ }^{21}$ En la SAP de Asturias de 20 de abril de 2018, al no quedar acreditada la remisión, a la dirección del contrato de un previo requerimiento de pago con la advertencia expresa de inclusión en ficheros de solvencia, se considera que la inclusión de los datos en un registro de morosos no es legítima. Tal decisión fue confirmada por la sts (Sala 1a) de 23 de abril de 2019.
} 
Es importante recordar la idea ya adelantada de que el principio de calidad de los datos no se limita a exigir la veracidad de la deuda. ${ }^{22}$ Es preciso la pertinencia de los datos respecto de la finalidad del fichero. No puede tratarse de un mero ejercicio de coacción. De ahí que las ssts (Sala 1a) de 29 de enero de 2013, 22 de diciembre de 2015 o 1 de marzo de 2016, entre otras, descansen sobre los principios de prudencia y ponderación, además de la veracidad, pues no cabe incluir en estos registros deudas inciertas, dudosas, no pacíficas o sometidas a litigio. ${ }^{23}$

El razonamiento parte de que, si una deuda es objeto de controversia, porque el titular de los datos entiende legítimamente que no debe lo que se le reclama, la falta de pago no es indicativa sin más de la insolvencia del afectado. Puede que la deuda resulte finalmente cierta y por tanto pueda estimarse como un dato veraz. Pero no era un dato pertinente y proporcionado a la finalidad del fichero automatizado, visto que este no tiene por finalidad la simple constatación de las deudas, sino de la solvencia patrimonial de los afectados. ${ }^{24}$

De todas formas, es preciso tener en cuenta que no es necesario que exista una condena judicial firme ${ }^{25}$ para que los datos personales relativos a una deuda sean introducidos en un registro. En virtud de ello, la sTs (Sala 1a) del 1 de marzo de 2016 razona que el hecho de que el acreedor no pueda utilizar la inclusión de los datos de su cliente en un fichero de morosos como medio de presión para que este pague una deuda que es legítimamente cuestionada por este, no supone que sea necesario en todo caso una sentencia condenatoria firme para realizar tal inclusión (punto 7 del Fundamento de Derecho quinto).

Así las cosas, la cuestión se ancla en una necesaria ponderación de intereses de modo casuístico, a partir de la observación de unos requisitos que Mas Badia califica de preceptivos (certeza de los datos y finalidad), puesto que operan en

${ }^{22}$ La STS (Sala 1a) de 23 de marzo de 2018 entiende que el pago parcial de las facturas discutidas no constituye un reconocimiento de la veracidad de las deudas.

${ }^{23}$ En la SAP de Barcelona de 5 de febrero de 2018, fue determinante para considerar que la inclusión fue indebida el hecho de que la demandante haya solicitado en reiteradas ocasiones la documentación acreditativa de la deuda, sin que la compañía telefónica demandada atendiera ninguno de esos requerimientos, ni tan siquiera el judicial.

${ }^{24}$ Sentencia del Juzgado de Primera Instancia núm. 3 de Badajoz de 16 de julio de 2018. Consultada en el Diario La Ley, núm. 9266, Sección Jurisprudencia, 25 de septiembre de 2018. Reconoce la vulneración o intromisión ilegítima en el derecho al honor del demandante y condena a las demandadas solidariamente a abonar al actor en concepto de daños morales derivados de tal a atentado al derecho al honor a la suma de 6000 euros.

${ }^{25}$ La STs (Sala 3a', Contencioso Administrativo, Sección 6) del 15 de julio de 2010 anuló la parte del artículo 38.1 del Real Decreto que exigía para la inclusión de los datos del deudor en el registro de morosos que no se hubiera entablado reclamación judicial, arbitral o administrativa respecto de deuda. 
todo caso, y que deben unirse al análisis del interés legítimo del responsable del tratamiento de un tercero. ${ }^{26}$

En todo caso, como se podrá percibir en la jurisprudencia analizada en este estudio, la exigencia de un examen casuístico no dista de forma significativa de la interpretación judicial de los preceptos vigentes. Ello no podría ser de otra forma desde las Sentencias del Tribunal de Justicia de la Unión Europea de 24 de noviembre de 2011 (Caso Asnef) ${ }^{27}$ y de 19 de octubre de 2016 (Caso Breyer). ${ }^{28}$

En otro orden de cosas, la obligación de informar al deudor es esencial para el análisis previo de la legitimidad de la inclusión. El artículo 20.1 c) de la LOPD de 2018 ofrece la posibilidad de informar al afectado en el contrato o en el momento de requerir el pago acerca de la posibilidad de inclusión en dichos sistemas, con indicación de aquéllos en los que participe. Parece dar, de esa manera, carta de naturaleza a las cláusulas genéricas que avisan de la posibilidad de ser incluidos en ficheros de información crediticia a los que está adherida la empresa acreedora.

Respecto al interés legítimo de acceso, la letra f) del artículo 6.1 REPD dispone que cuando el tratamiento es necesario para la satisfacción de intereses legítimos perseguidos por el responsable del tratamiento o por un tercero, será lícito, siempre que sobre dichos intereses no prevalezcan los intereses o derechos y libertades fundamentales del interesado que requieran la protección de datos personales. En esa línea, la letra d) del artículo 20 de la LoPD de 2018 determina que los datos referidos a un deudor determinado solamente pueden ser consultados cuando quien consulte el sistema mantenga una relación contractual con el afectado que implique el abono de una cuantía pecuniaria o este le hubiera solicitado la celebración de un contrato que suponga financiación, pago aplazado o facturación periódica, como sucede, entre otros supuestos, en los previstos en la legislación de contratos de crédito al consumo y de contratos de crédito inmobiliario.

\section{5. El honor como derecho fundamental vulnerado}

Son dos los derechos fundamentales afectados por la inclusión indebida: por una parte, el derecho a la protección de los datos personales; por otra, el honor. La jurisprudencia civil se ha centrado en este último aspecto, $\mathrm{y}$, con

\footnotetext{
${ }^{26}$ MAS BADIA, MARía DoloRES, "Los sistemas de información crediticia y la protección de datos personales: un Reglamento europeo y una Ley Orgánica concebida y no nacida", Actualidad Civil, núm. 5, pp. 4-7.

${ }^{27}$ Asuntos acumulados C-468/10 y C-469/10.

${ }^{28}$ Asunto C-582/14.
} 
carácter general, entiende que no está afectada la intimidad. En esa línea, la sTs (Sala 1a) de 9 de abril de 2012, al igual que la sts (Sala 1a) de 9 de marzo de 2013, afirma que el derecho vulnerado es el honor y no la intimidad, pues la inclusión en un registro de morosos afecta directamente la dignidad en cuanto representa un notorio descrédito.

El derecho al honor es valorado tanto en su dimensión subjetiva de autoestima como en su faceta objetiva de reputación personal y profesional, ya que es indiscutible que la divulgación de una falsa morosidad lesiona la dignidad de la persona, menoscaba su fama y atenta a su propia estimación.

Asimismo, si bien la LopD contemple exclusivamente los derechos fundamentales de las personas físicas, no está de menos recordar que es doctrina pacífica en los tribunales españoles ${ }^{29}$ la protección del honor de las personas jurídicas de derecho privado en el marco de la lo $1 / 1982 .{ }^{30}$

La Sentencia del Pleno del ts de 24 de abril del 2009 sentó doctrina en el sentido de que el derecho fundamental vulnerado es el honor y que la mera inclusión ya es en sí misma una vulneración, con independencia de que el fichero haya sido consultado o no: "Esta Sala, en pleno, ha mantenido la posición de entender que la inclusión, faltando a la veracidad, por una entidad, en un registro de solvencia patrimonial [los llamados "registros de morosos"] implica un atentado al derecho del honor del interesado que ha aparecido en tal registro, erróneamente."

El caso que dio lugar a esta doctrina arranca del hecho de que una entidad de crédito realizó un cargo indebido, pues no correspondía a ninguna operación realizada por la afectada en su cuenta corriente. La entidad bancaria exigió la deuda con sus intereses y gastos e inscribió a la demandante en dos registros de morosos durante doce días.

\section{Alcance de la reparación: daños patrimoniales y morales}

El REPD, en su artículo 82, determina que "Toda persona que haya sufrido daños y perjuicios materiales o inmateriales como consecuencia de una infracción del presente Reglamento tendrá derecho a recibir del responsable o el encargado del tratamiento una indemnización por los daños y perjuicios sufridos”. En todo caso, la jurisprudencia más significativa es aquella derivada de demandas

\footnotetext{
${ }^{29}$ Avalada por la Sentencia del Tribunal Constitucional de 26 de septiembre de 1995 "la persona jurídica puede también ver lesionado su derecho al honor a través de la divulgación de hechos concernientes a su identidad, cuando la difame o la haga desmerecer en la consideración ajena (artículo 7.7 Lo/1982)".

${ }^{30}$ Sobre ese tema, véase Yzouierdo Tolsada, Mariano, "Daños a los derechos de la personalidad (honor, intimidad y propia imagen)", en Tratado de Responsabilidad Civil, Cizur Menor (Navarra), 2014, pp. 61-65.
} 
con base en la vulneración del derecho al honor de acuerdo con la lo 1/1982, que proclama en su artículo 9.3 que la existencia de perjuicio se presumirá siempre que se acredite la intromisión ilegítima.

Considerando los casos de vulneración del derecho al honor, en lo concerniente al elemento subjetivo, un análisis de la normativa de protección de datos nos permite detectar una serie de sujetos implicados en la cuestión. Así, por lo que a la responsabilidad civil interesa, están, como mínimo, el afectado, el acreedor que proporciona los datos de solvencia, y los prestadores de servicios sobre información de solvencia patrimonial encargados del tratamiento o que contratan dicho tratamiento con otra empresa.

En un número importante de las sentencias analizadas, hasta la sTs (Sala 1a) de 21 de mayo de 2014, la demanda y la respectiva condena, en caso de que fuese acogida la tesis de la parte demandante, iban dirigidas exclusivamente a la entidad acreedora que había proporcionado los datos de la deuda al registro de morosos. Sin embargo, desde referido fallo, empezó a diseñarse una responsabilidad solidaria de los prestadores de servicios del tratamiento de los datos personales. En el supuesto concreto se establece que Equifax no es un mero encargado del tratamiento de datos que actúa por cuenta y bajo las órdenes de un responsable del fichero, de modo que no es aceptable la tesis de que el responsable del fichero común carece de disponibilidad sobre los datos registrados y, por tanto, de responsabilidad.

Esa interpretación está en consonancia con lo marcado por la Sentencia del Tribunal de Justicia de la Unión Europea, del 13 de mayo de 2014, sobre el "derecho al olvido" en internet, pues en la misma se interpreta que el gestor del motor de búsqueda se considera responsable del tratamiento de los datos.

Sigue esa orientación, y más allá de la responsabilidad referida a los derechos de acceso, rectificación y cancelación, una sentencia del Juzgado de Primera Instancia número 3 de Badajoz del 16 de julio de 2018, anteriormente citada, que condenó solidariamente a la compañía telefónica y al registro de morosos por daños morales al afectado, por la inserción indebida de sus datos en el fichero. Mantiene, siguiendo la doctrina jurisprudencial indicada, que Asnef Equifax no es solo un mero encargado del tratamiento de datos sin autonomía en la toma de decisiones, sino que debió dar respuesta fundada al derecho de cancelación ejercitado por el interesado. En el caso expuesto, incumplió el deber de supervisión que le incumbía. El usuario le advirtió expresamente de lo incierto de la deuda y de la ausencia de notificación y requerimiento de pago por parte de la compañía y, aun así, denegó su solicitud de cancelación. 
Por lo que atañe al elemento objetivo, apreciada la intromisión ilegítima en el derecho al honor es preciso determinar la existencia de daños patrimoniales y morales, según las circunstancias de cada caso.

Entramos en un campo muy casuístico, marcado por un amplio margen de apreciación por los tribunales, como pusieron de manifiesto las SSTS (Sala 1a) del 9 de abril de 2012 y 7 de noviembre de 2018.

En clave de reparación integral del daño, la doctrina jurisprudencial sentada en el STs (Pleno) de 29 de abril de $2009^{31}$ resumida en las SSTs (Sala $1^{\text {a) }}$ de 18 de febrero y 12 de mayo de 2014, seguida en la SAP de Palencia del 26 de abril de $2018^{32}$ mantiene que:

La indemnización debe incluir el daño patrimonial y dentro de él, tanto los daños patrimoniales concretos, fácilmente verificables y cuantificables, por ejemplo el derivado de que el afectado hubiera tenido que pagar un mayor interés por conseguir financiación al estar incluidos sus datos personales en uno de estos registros, como los daños patrimoniales más difusos pero también reales e indemnizables, como son los derivados de la imposibilidad o dificultad para obtener el crédito o contratar servicios (puesto que este tipo de registros está destinado justamente advertir a los operadores económicos de los incumplimientos de obligaciones dinerarias por las personas cuyos datos han sido incluidos en ellos). ${ }^{33}$

Asimismo, se deben tener en cuenta los daños derivados del desprestigio y deterioro de la imagen de solvencia personal y profesional causados por dicha inclusión en el registro, cuya cuantificación ha de ser necesariamente estimativa (daños morales). ${ }^{34}$

Ahora bien, todos estos extremos, patrimoniales y morales, no siempre son fáciles de evaluar económicamente, ${ }^{35}$ siendo fijados, en la mayor parte de los casos aquí reseñados, exclusivamente daños morales.

\footnotetext{
${ }^{31}$ La sts (Sala 1a) del 29 de abril de 2009 sienta el criterio de que dentro de la indemnización hay que distinguir entre daño moral y el daño patrimonial -como podrian ser las consecuencias económicas derivadas de la negación de un préstamo-, aunque en el caso que resuelve se impusieron únicamente los daños morales, por razones de congruencia, ya que el demandante había solicitado exclusivamente la reparación no patrimonial.

${ }^{32}$ Confirmada por la sTs (Sala 1a) de 20 de febrero de 2019.

${ }^{33}$ La SAP de Baleares del 11 de diciembre de 2017 fijó una indemnización de 7000 euros por la imposibilidad de contratar con otra entidad.

${ }^{34}$ Véase Sarazá Jimena, Rafael, "Responsabilidad civil por la indebida inclusión en un registro de morosos", Revista Aranzadi Doctrinal, num. 7, pp. 105-132.

${ }^{35}$ Rubio Torrano, Enrique, "Daño moral por inclusión indebida en registro moroso: Indemnización de carácter meramente simbólico", Revista Doctrinal Aranzadi Civil-Mercantil, núm. 11, p. 23.
} 
La vulneración del derecho del honor provoca daños consistentes en la afectación de la dignidad tanto en su aspecto interno o subjetivo como en el externo u objetivo, relativo a la consideración de las demás personas. De igual modo, provoca daños consistentes, como relata la STS (Sala 1a) del 21 de junio de 2018 en el 23 y la angustia producida por las gestiones más o menos complicadas que haya tenido que realizar el afectado para lograr la rectificación o cancelación de los datos incorrectamente tratados. ${ }^{36}$

En lo que se refiere a la cuantía de la indemnización de los daños morales, la STs (Sala 1 ${ }^{\text {a }}$ ) de 19 de noviembre de 2014 declaró que su valoración no pude obtenerse de una prueba objetiva, pero ello no imposibilita legalmente para fijar su cuantificación, a cuyo efecto han de ponderarse las circunstancias concurrentes en cada caso. Se trata, por ende, de una valoración estimativa, que en el caso de daños morales derivados de la vulneración de un derecho fundamental del artículo 18.1 ce, ha de atender a los parámetros previstos en el artículo 9.3 de la lo $1 / 82$, utilizando criterios de prudente arbitrio. ${ }^{37}$

LAS SSTS (Sala $1^{\text {a }}$ ) de 18 de febrero y de 12 de mayo de $2015^{38}$ son especialmente interesantes para conocerlos. Así, es preciso valorar los siguientes aspectos:

a) Duración de la inclusión indebida de los datos del afectado en el fichero en cuestión. ${ }^{39}$

b) Cantidad de ficheros en los que ha sido incluido.

c) La difusión que han tenido esos datos mediante la cantidad de visitas o consultas efectuadas al fichero, por empresas que quisieran conocer la situación de morosidad del afectado.

Es verdad que la sts (Sala 1a) de 24 de abril de 2009 determina que hay intromisión ilegítima en el derecho al honor de una persona desde el momento en que se le incluye de forma indebida en un registro de morosos, aunque esta circunstancia no haya sido objeto de consultas, pues basta la posibilidad de conocimiento público. Con todo, el alcance de la difusión sí será relevante a la hora de determinar el alcance de la indemnización.

\footnotetext{
${ }^{36} \mathrm{Cfr}$. también las ssts (Sala 1a) del 6 de noviembre de 2018 y 23 y 25 de abril de 2019.

${ }^{37}$ Véase la SAP de Sevilla del 15 de marzo de 2018.

${ }^{38}$ Es preciso mencionar las ssis (Sala 1a) del 9 de abril de 2012 y 6 de marzo de 2014.

${ }^{39}$ Como explicita la sts (Sala 1a) del 6 de noviembre de 2018, ha de tomarse en consideración la divulgación que ha tenido tal dato, pues no es lo mismo que solo hayan tenido conocimiento los empleados de la empresa acreedora y los de las empresas responsables de los registros de morosos que manejan los correspondientes ficheros, a que el dato haya sido comunicado a un número mayor o menor de asociados al sistema que hayan consultado los registros de morosos.
} 
Como pone de manifiesto la sts (Sala 1a) del 18 de febrero de 2015, "ha de tomarse en consideración la divulgación que ha tenido tal dato, pues no es lo mismo que sólo hayan tenido conocimiento los empleados de la empresa acreedora y los de las empresas responsables de los registros de morosos que manejan los correspondientes ficheros, a que el dato haya sido comunicado a un número mayor o menor de asociados al sistema que hayan consultado los registros de morosos". ${ }^{40}$

d) Tipo de empresas que han consultado los ficheros.

e) El proceso más o menos complicado que hubiese tenido que seguir el afectado para la rectificación o cancelación de los datos incorrectamente tratados. Las dificultades de las gestiones realizadas por el afectado, para conseguir ejercitar su derecho de cancelación son objeto de detallado análisis, ya que en algunos casos les fue imposible, pues la compañía confirmaba dicha inclusión ante el requerimiento del afectado, como en el litigio resuelto en la SAP Sevilla del 15 de marzo de 2018.

En todo caso, la escasa cuantía de la deuda no disminuye la importancia del daño moral. Como se desprende de la sTs (Sala 1a) del 26 de abril de 2017, la inclusión en registros de morosos por deudas de pequeña cuantía es correcta y congruente con la finalidad de informar sobre la insolvencia del deudor y el incumplimiento de sus obligaciones dinerarias. Por tanto, es lógico que, en los supuestos de inclusión indebida, la reducida cuantía de la deuda no disminuya la importancia del daño moral causado. ${ }^{41}$

Por último, tampoco cabe tener en cuenta que no conste que la inclusión indebida haya impedido a la recurrente acceder a créditos o servicios (sSTs, Sala 1a del 27 de abril de 2016 y 21 de junio de 2018), pues el daño moral es independiente de los perjuicios materiales.

\section{Daños morales e indemnizaciones simbólicas}

La jurisprudencia de la Sala $1^{\text {a }}$ considera que no son admisibles las indemnizaciones de carácter simbólico, porque estamos en presencia de derechos fundamentales protegidos con rango constitucional como derechos reales y efectivos. ${ }^{42}$ La admisión de valores resarcitorios simbólicos convertiría la garantía

\footnotetext{
${ }^{40} \mathrm{Cfr}$. sts (Sala 1a) del 18 de febrero de 2015 y sap Asturias del 7 de mayo de 2018.

${ }^{41}$ Como ocurre en la sts (Sala 1a) del 23 de abril de 2019.

${ }^{42}$ Para los derechos fundamentales, en general, la Sala $1^{\text {a }}$ ha tenido la oportunidad de manifestarse en varias ocasiones, siempre a propósito de litigios sobre intromisión en los derechos al honor, intimidad personal y familiar y propia imagen, en contra de las indemnizaciones meramente simbólicas. Cfr. SSTS (Sala 1a) del 18 de noviembre de 2002, 28 de abril de 2003 y 12 de diciembre de 2011.
} 
jurisdiccional en un acto meramente ritual o simbólico incompatible con el contenido de los artículos 9.1,1.1. y 53.2 cE y la correlativa exigencia de una reparación acorde con el relieve de los valores e intereses en juego. ${ }^{43}$

Entiende que una indemnización simbólica puede provocar, según las circunstancias, un valor disuasorio inverso, pues, como explica la STS (Sala 1 ${ }^{\text {a) }}$ del 21 de septiembre de 2017, disuade a las empresas de incluir indebidamente datos, pero sí disuade de entablar una demanda a los afectados. En este punto, es muy acertado el razonamiento de la sTs (Sala $1^{\text {a) }}$ del 4 de diciembre de 2014 cuando expresa que la reparación simbólica desincentiva la adopción de pautas de conducta más profesionales y serias por parte de las empresas implicadas en la cesión y el tratamiento de datos, ya que en un sencillo análisis económico de las consecuencias de sus malas praxis se encuentran con que es más rentable seguir con las mismas, en la medida en que es más barato pagar una indemnización que invertir en la mejora del sistema.

Es posible visibilizar toda la extensión de la problemática planteada en la STS (Sala 1a) del 21 de junio de 2018. En ese caso, la demandante interpone contra la empresa Intrum Justitia DBT Finance AG una demanda para la protección de los derechos fundamentales, en concreto, del derecho al honor por la inclusión en un fichero de morosos. Solicitó que se declarara que la demandada ha cometido una intromisión ilegítima en su honor y se le indemnizara la cantidad de 10000 euros por daños morales. En primera instancia, se acogió la argumentación de la demandante y se fijó una indemnización de 10000 euros por daños morales, teniendo en cuenta el tiempo que estuvo incluida en el fichero (un año), y que accedieron al mismo entidades bancarias y de crédito, entre ellos Liberbank, que denegó a la actora un préstamo de 48000 euros y Cesce, que analizó el riesgo de la actora y rebajó su grado de solvencia. Posteriormente, fue reducida, en apelación, a 2000 euros, en función del poco tiempo en que estuvo incluida en el fichero, los indicios de veracidad de la deuda y la no acreditación de perjuicios económicos reales.

Ante esa rebaja significativa, la Sala $1^{\text {a }}$ del Tribunal Supremo analizó los criterios de fijación de la indemnización, apoyada en su doctrina constante de que la determinación de la cuantía de las indemnizaciones por resarcimiento de daños morales en este tipo de procedimientos es competencia de los tribunales de instancia, cuya decisión al respecto ha de respetarse en casación, salvo

\footnotetext{
${ }^{43}$ SSTS (Sala 1a) del 4 de diciembre de 2014 y 26 de abril de 2017, en la línea marcada por la Sentencia del Tribunal Constitucional 186/2001, de 17 de septiembre.
} 
que no se hubiera atenido a los criterios que establece el artículo 9.3 lo 1/82 o, en caso de error evidente, arbitrariedad o notoria desproporción. ${ }^{44}$

El Tribunal Supremo mantiene la doctrina expuesta, y se centra en el efecto inverso de las indemnizaciones simbólicas. En el análisis del supuesto enjuiciado, consta que el fichero fue consultado en once ocasiones, entre el 13 de abril de 2015 y 29 de febrero de 2016, en concreto tres veces, por Banco Popular, una vez por Barclays Bank PLC, una vez por Liberbank y tres veces por Cesce.

En vista de ello, reconoce que la indemnización fijada por la Audiencia es simbólica y que no puede cuantificarse en 2000 euros, en atención a las circunstancias del caso. Ahora bien, no confirma la valoración de instancia. En ese sentido, el aumento del montante fue algo inferior a las sentencias de contraste, pues las circunstancias de los casos no son totalmente idénticas, en cuanto a que en esta ocasión solo se incluye el dato en un registro de morosos y su difusión es algo menor. ${ }^{45}$ Por ese motivo, el fallo del Ts fija una indemnización de 6000 euros. ${ }^{46}$

\section{Conclusiones}

El creciente aumento de demandas ante los tribunales relacionadas con posibles intromisiones ilegítimas en el derecho al honor de consumidores o de pequeñas empresas, y el análisis de la doctrina jurisprudencial sobre la materia, invita a una reflexión crítica sobre el actual marco normativo de la protección de datos personales.

Aprovechando la entrada en vigor del REPD y de la LOPD de 2018, es el momento de promover mecanismos más adecuados a las legítimas expectativas de protección del derecho al honor frente a intromisiones ilegítimas por inclusiones indebidas en registros de morosos.

Ello se puede conseguir con un mayor rigor en la exigencia del respeto al principio de calidad de los datos personales, sin con ello limitar excesivamente el mecanismo legítimo de información sobre la solvencia patrimonial de deudores. El REPD y la vigente LOPD promueven una responsabilidad proactiva de los

\footnotetext{
${ }^{44}$ Notoria desproporción como la manifestada en el caso resuelto por la sTs (Sala 1a) del 4 de diciembre del 2014. La indemnización fijada por la Audiencia Provincial, que confirma la del Juzgado de Primera Instancia fue de 300 euros. Se entendió meramente simbólico por el Ts, habida cuenta de los actuales parámetros sociales y económicos.

${ }^{45}$ La sts (Sala 1a) de 18 de febrero de 2015 fijó una indemnización de 10000 euros, y de 12000 euros en la sts (Sala 1a) de 5 de junio de 2014.

${ }^{46}$ En el caso resuelto por la sts (Sala 1a) del 20 de febrero de 2019 "no se aprecia que la indemnización fijada sea contraria, de modo notable, a los parámetros jurisprudenciales, ni merezca el calificativo de simbólica, si se tienen en cuenta resoluciones de la sala que cuantifican daños morales en $6.000 €$ (sts de 21 de junio); $3.000 €$ (sTs de 7 de noviembre de 2018) y $1.000 €$ (sts de 6 de noviembre de 2018), bien es cierto que se habrá de estar a las circunstancias de cada caso".
} 
responsables del tratamiento de datos que, de ese modo, deben garantizar su licitud, lealtad y transparencia, y que su finalidad sea determinada, adecuada, pertinente y relativa a datos exactos. En esa línea se encuentra el régimen de los responsables y encargados del tratamiento, en particular, la creación de la figura del delegado de Protección de Datos en determinadas entidades, así como la previsión de los códigos de conducta y certificación.

De la jurisprudencia analizada, entiendo muy positiva la doctrina jurisprudencial que rechaza la reparación simbólica, puesto que atiende al propósito de evitar que exista el denunciado incentivo inverso, aportando más argumentos de oportunidad legislativa para el incremento de los mecanismos preventivos de los daños.

Por último, y cuando no se pueda eludir las intromisiones ilegítimas, se deberían promover los mecanismos de mediación en asuntos civiles y mercantiles, especialmente la mediación de consumo, cuando corresponda, para reducir la judicialización de los conflictos.

\section{Bibliografía}

Álvarez Olalla, Pilar, "La obligación de evaluar la solvencia y su incumplimiento", en Matilde Cuena Casas y Vicente Alcañiz Miñano (coords.), La prevención del sobreendeudamiento privado. Hacia un préstamo y consumo responsables, Cizur Menor, Thomson Reuters Aranzadi, 2017.

Chaparro Matamoros, Pedro, "Sentencia de 12 mayo 2015", Cuadernos Civitas de Jurisprudencia Civil, núm. 100.

Cuena Casas, Matilde, "Fresh Start y mercado crediticio", InDret, núm. 3.

Hualde Manso, María Teresa, "Ficheros de morosos, nulidad del Reglamento de

Protección de Datos y derecho al honor", Revista Doctrinal Aranzadi CivilMercantil, vol. 2, núm. 8.

Mas Badia, María Dolores, "Los sistemas de información crediticia y la protección de datos personales: un Reglamento europeo y una Ley Orgánica concebida y no nacida”, Actualidad Civil, núm. 5.

202 Parra Lucan, M. a Ángeles, "Vulneración del derecho al honor por incorrecta inclusión en un fichero de morosos: Sentencia del Tribunal Supremo de 24 de abril del 2009”, en Mariano Yzquierdo Tolsada (dir.), Comentarios a las sentencias de unificación de doctrina: civil y mercantil, Madrid, Dykinson, 2009.

Rubio Torrano, Enrique, "Daño moral por inclusión indebida en registro moroso: Indemnización de carácter meramente simbólico", Revista Doctrinal Aranzadi Civil-Mercantil, núm. 11.

SARAZÁ Jimena, RAfael, "Responsabilidad civil por la indebida inclusión en un registro de morosos”, Revista Aranzadi Doctrinal, núm. 7. 
Yzquierdo Tolsada, Mariano, "Daños a los derechos de la personalidad (honor, intimidad y propia imagen)", en Tratado de Responsabilidad Civil, Cizur Menor (Navarra), 2014. 